Published in final edited form as:

Zhang, G., Li, G., Lan, Z.-A., Lin, L., Savateev, A., Heil, T., et al. (2017). Optimizing Optical Absorption, Exciton Dissociation, and Charge Transfer of a Polymeric Carbon Nitride with Ultrahigh Solar Hydrogen Production Activity. Angewandte Chemie International Edition. doi:10.1002/anie.201706870.

\title{
Optimizing Optical Absorption, Exciton Dissociation, and Charge Transfer of a Polymeric Carbon Nitride with Ultrahigh Solar Hydrogen Production Activity
}

Guigang Zhang, Guosheng Li, Zhi-An Lan, Lihua Lin, Aleksandr Savateev, Tobias Heil, Spiros Zafeiratos, Xinchen Wang and Markus Antonietti

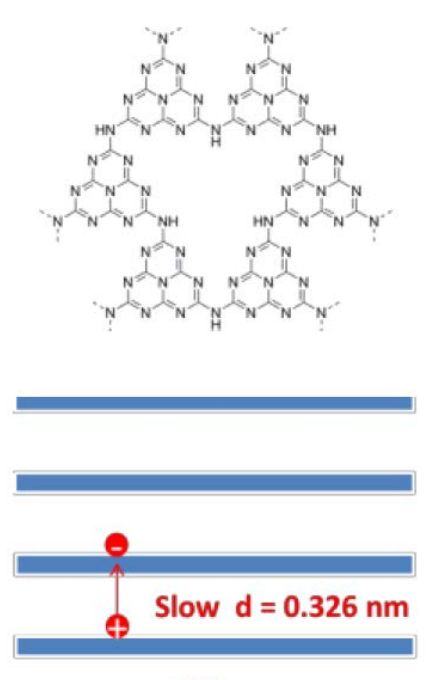

CN
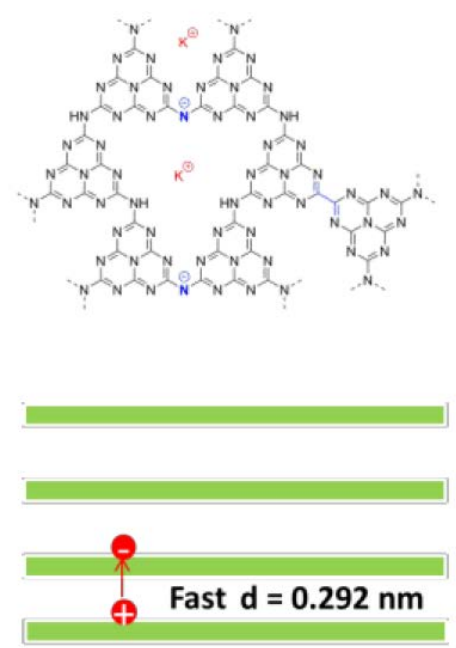

CN-OA-m

\section{COMMUNICATION}

The simultaneous modification in the electronic band structures, layer-stacking geometry and crystallinity of carbon nitride polymers enables the liberation of Frenkel exciton dissociation and magnification of hot charges yield, which dramatically promotes the visible light photocatalytic activities and enriches the carbon nitride family. 


\title{
Optimizing Optical Absorption, Exciton Dissociation, and Charge Transfer of a Polymeric Carbon Nitride with Ultrahigh Solar Hydrogen Production Activity
}

\author{
Guigang Zhang, ${ }^{*[a]}$ Guosheng Li, ${ }^{[b]}$ Zhi-An Lan, ${ }^{[b]}$ Lihua Lin, ${ }^{[b]}$ Aleksandr Savateev, ${ }^{[a]}$ Tobias Heil, ${ }^{[a]}$ \\ Spiros Zafeiratos, ${ }^{[c]}$ Xinchen Wang ${ }^{*[b]}$ and Markus Antonietti ${ }^{*[a]}$
}

Abstract: Polymeric or organic semiconductors are promising candidates for photocatalysis, but mostly only show moderate activity due to strongly bound excitons and insufficient optical absorption. Herein, we report a facile bottom-up strategy to improve the activity of a carbon nitride to a level where a majority of photons are really used to drive photoredox chemistry. Co-condensation of urea and oxamide followed by post-calcination in molten salt is shown to result in highly crystalline species with $\pi-\pi$ layer stacking distance of heptazine units of maximal $0.292 \mathrm{~nm}$, this improving lateral charge transport and interlayer exciton dissociation. The addition of oxamide decreases the optical band gap from 2.74 to $2.56 \mathrm{eV}$, which is shown to enable efficient photochemistry also with green light. The apparent quantum yield (AQY) for $\mathrm{H}_{2}$ evolution of optimal samples reaches $57 \%$ and $10 \%$ at $420 \mathrm{~nm}$ and $525 \mathrm{~nm}$, respectively, which is significantly higher than most previous experiments.

Polymeric photocatalysts, e.g. melon-based carbon nitrides (CN), with their optical and electronic properties being feasibly tuned by controlling the polymerization process, have recently found fascinating utilizations for photocatalytic $\mathrm{H}_{2}$ production from water. $^{[1-7]}$ To obtain sufficient solar-to-energy efficiency, it calls for the fast generation of photo-excited charge carriers, i.e. the hot electrons and holes, which are involved in the subsequent water splitting redox reactions. However, like most conjugated polymers which are normally restricted by the intrinsic strong Coulomb interactions of singlet Frenkel excitons, $\mathrm{CN}$ also bear sluggish exciton dissociation, indicating a high exciton binding energy $\left(E_{b}\right)$. This is why bulk $C N$ in most cases only presents moderate photoactivities. Plenty of strategies have been developed to improve the photocatalytic activity of $\mathrm{CN}$ in the past few years, ${ }^{[8-17]}$ always progressing to more efficient systems. In principle, the layer stacking distance is theoretically predicted to dominate the interlayer exciton dissociation and thus charge mobility. ${ }^{[18-20]}$ In comparison with graphite, the $\pi-\pi$ stacking distance in disordered melon is typically a $0.326 \mathrm{~nm}, 5 \%$

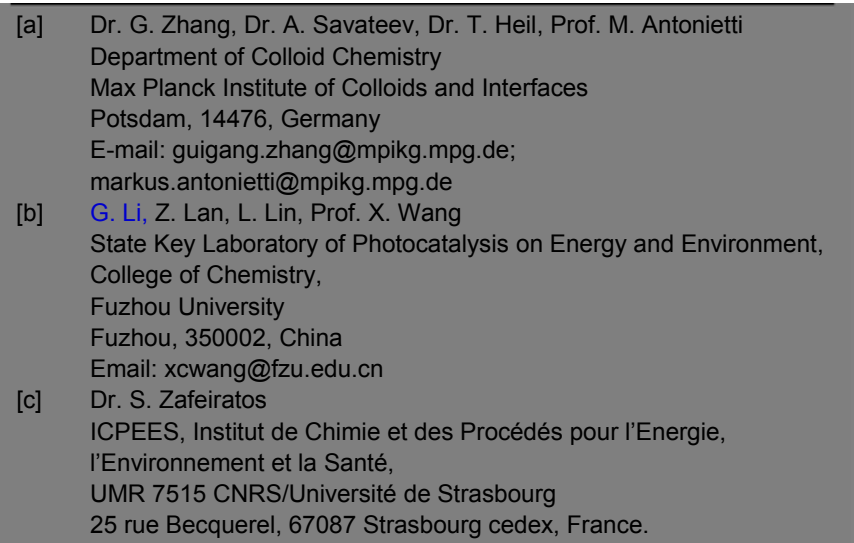

tighter than in crystalline graphite. Note that shorter distances in chemistry can usually be attributed to additional bonding schemes, here presumably intense polarization and/or charge transfer (CT) interactions between two layers, i.e. partial plus and minus charges on neighboring layers enable tighter packing and promote charge and energy transport within the stacks. Indeed, the stacking distance was already varied in the range of $0.1 \AA$ by optimization the preparation process, ${ }^{[21]}$ such as elevating the condensation temperature. For instance, when increasing the polymerization temperature from $773 \mathrm{~K}$ to $823 \mathrm{~K}$, slightly decreased stacking distance (from 0.326 to $0.323 \mathrm{~nm}$ ) could be observed. ${ }^{[22]}$ Breakthroughs in the stacking distance are expected to revolve around the rational modification of the synthetic strategy. Actually, the stacking distance was compressed from 0.326 to $0.32 \mathrm{~nm}$ by performing the polymerization process in molten salt to accelerate the sluggish deamination process, resulting in potassium salt formation at the same time. ${ }^{[23]}$ Interestingly, the resulting materials turn out to be very effective for photocatalytic $\mathrm{H}_{2}$ evolution. This provides a sought-for alternative way to improve the polycondensation process by "cooking" suitable starting materials in eutectic salt mixtures with lower melting point to turn at least parts of a solid state condensation process into solution chemistry.

Beside interlayer exciton splitting, also intralayer processes can contribute to better charge handling, mainly by locating domains with different electron affinity in the plane. In organic polymer photovoltaics, this is known under the term "donoracceptor" (D-A) polymers. ${ }^{[24]}$ Also in 2D modified melon, strategies such as doping ${ }^{[25-27]}$ or copolymerization ${ }^{[28-30]}$ could create such 2D D-A structures with significantly increased charge carrier yield. In addition, such D-A-modification shifts the optical absorption into the red region and sometimes even allows photochemical reactions in this spectral region.
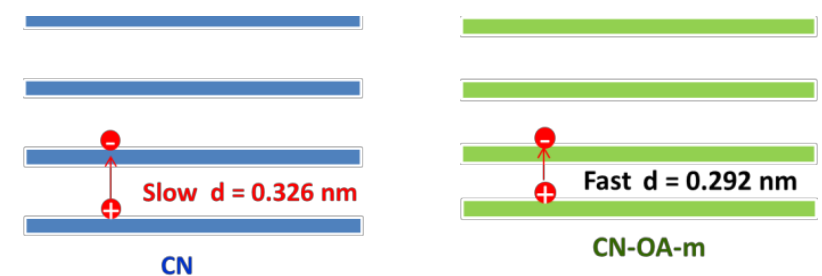

Scheme 1. Proposed interlayer charge carrier transfer of (left) pristine $\mathrm{CN}(\mathrm{d}=$ $0.326 \mathrm{~nm}$ ) and (right) optimized CN-OA-m with shortened layer stacking distance $(\mathrm{d}=0.316 \mathrm{~nm})$.

The current proof-of-concept demonstration can be seen in Scheme 1 and $\mathrm{S} 1$. We found out that by co-condensation of simple urea with oxamide $(\mathrm{OA})$ in molten salt mixtures $(\mathrm{KCl} / \mathrm{LiCl})$, this issue could be easily attacked. In this system, we found diverse packing motifs, with the interlayer stacking distance could be reduced from 0.326 to $0.292 \mathrm{~nm}$. Besides, the visible 
light absorption threshold of the as-prepared copolymers could be extended to as long as $650 \mathrm{~nm}$, which is shown to do access also those photons for photochemistry
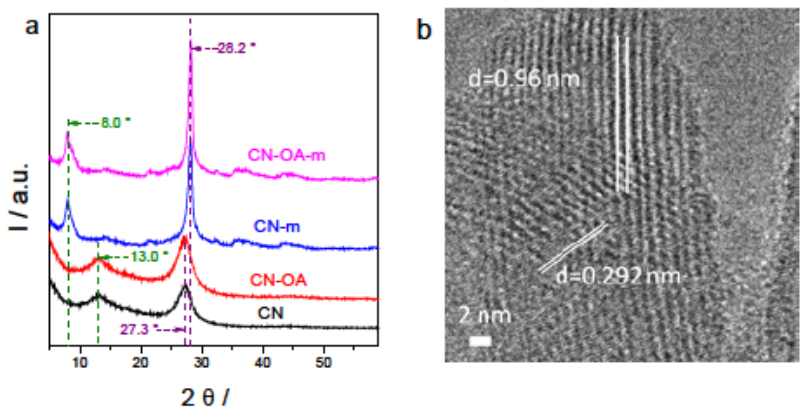

Figure 1. (a) Powder XRD patterns of $\mathrm{CN}, \mathrm{CN}-\mathrm{OA}, \mathrm{CN}-\mathrm{m}$, and $\mathrm{CN}-\mathrm{OA}-\mathrm{m}$, (b) HR-TEM image of CN-OA-m.

Typically, $\mathrm{CN}$ was prepared from urea while $\mathrm{CN}-\mathrm{OA}$ was obtained from urea and oxamide. $\mathrm{CN}-\mathrm{m}$ and $\mathrm{CN}-\mathrm{OA}-\mathrm{m}$ are corresponding samples prepared in molten salts. To examine the layered-stacking mode of the as-synthesized polymers, powder XRD characterizations were in the first place conducted. As shown in Figure 1a, all the samples showed two distinct peaks while presented different peak location and intensity. Two identical peaks located at $13.0^{\circ}$ and $27.3^{\circ}$ corresponding to (100) interplanar packing of heptazine units and (002) $\pi-\pi$ interlayer stacking motif were recorded for $\mathrm{CN}$ and $\mathrm{CN}-\mathrm{OA} .^{[31,32]}$ The (100) peak was shifted from $13.0^{\circ}$ to $8.0^{\circ}$, revealing an extended interplanar packing distance of about $0.81 \mathrm{~nm}$ for CN-OA-m compared with $0.618 \mathrm{~nm}$ for pristine $\mathrm{CN}$. On the contrary, the (002) peak was moved up from $27.4^{\circ}$ to $28.2^{\circ}$, reflecting the fact that the interlayer stacking distance was compacted due to a strong van der Waals attraction between the neighboring heptazine layers. HR-TEM further demonstrates the evident change in the interlayer stacking distance. As shown in Figure $1 \mathrm{~b}$, we find for some remarkably crystalline species a heptazine $\pi-\Pi$ layer stacking (002) of CN-OA-m with apparent interlayer distances of $0.292 \mathrm{~nm}$. As polyheptazine units are slightly corrugated, this distance is to be taken with a grain of salt, but corresponding picture of pristine $\mathrm{CN}$ shows a stacking distance of $0.326 \mathrm{~nm}$. In this species, the in-plane arrangement distance of nitrogen-linked heptazine units (100) was observed to be 0.96 $\mathrm{nm}$, again much larger than that of pristine $\mathrm{CN}(0.618 \mathrm{~nm})$. The evident change in the stacking mode is most probably ascribed to well-condensed polymers with few structure defects, but also to simultaneous K-salt formation, as evidences with FT-IR, XPS and elemental analysis discussed below.

FT-IR shows that two new absorption bands at 987 and 1605 $\mathrm{cm}^{-1}$ related to the symmetric and asymmetric vibration of $\mathrm{NC}_{2}$ bonds in metal- $\mathrm{NC}_{2}$ groups are revealed for $\mathrm{CN}-\mathrm{m}$ and $\mathrm{CN}-\mathrm{OA}-$ $\mathrm{m}$ (Figure $\mathrm{S} 1),{ }^{[34]}$ certifying the presence of $\mathrm{K}-\mathrm{NC}_{2}$ groups. $\mathrm{C}, \mathrm{N}$, $\mathrm{K}$, and $\mathrm{O}$ four elements were examined by XPS analysis of the as-prepared $\mathrm{CN}-\mathrm{OA}-\mathrm{m}$ (Figure $\mathrm{S} 2$ ). Residual $\mathrm{K}$ is derived from molten salt and no chlorine is observed, consist with previous study. ${ }^{[23,34]}$ Compared with pristine $\mathrm{CN}, \mathrm{CN}-\mathrm{OA}-\mathrm{m}$ exhibits quite similar $\mathrm{C} 1 \mathrm{~s}$ and $\mathrm{N} 1 \mathrm{~s}$ spectra, implying the $\mathrm{sp}^{2}$ hybridized heptazine units were hardly changed after modification in the stacking geometry. The additional weak peak of N1s at $396.7 \mathrm{eV}$ is attributed to the negatively charged $\mathrm{C}-\mathrm{N}^{\ominus}-\mathrm{C}$ group, which could neutralize the positive $\mathrm{K}^{+}$(Figure $\mathrm{S} 2 \mathrm{c}$ ). Note that the metal location position may be different depending on the synthesis strategies. ${ }^{[34, b]}$ EELS spectra (Figure S3) reveal that both $\mathrm{CN}$ and $\mathrm{CN}-\mathrm{OA}-\mathrm{m}$ are composed of $\mathrm{sp}^{2}$-hybridized carbon and nitrogen atoms, as seen by the presence of a well-developed $1 \mathrm{~s} \rightarrow \pi^{*}$ transition for both carbon and nitrogen. ${ }^{[35]}$ The structural refinement in the molten salt also modifies the texture of the polymer crystals (Figure S4 and 5). SEM elemental mapping (Figure S6) confirms the homogeneous distribution of $\mathrm{C}, \mathrm{N}$ and $\mathrm{K}$ inside the material (Table S1). The $\mathrm{C} / \mathrm{N}$ molar ratio of $\mathrm{CN}-\mathrm{OA}$ $m(0.72)$ is slightly higher than that of pristine $C N(0.71)$. The specific surface area of CN-OA-m $\left(85 \mathrm{~m}^{2} \mathrm{~g}^{-1}\right)$ only weakly increased, when compared to pristine $\mathrm{CN}\left(63 \mathrm{~m}^{2} \mathrm{~g}^{-1}\right)$.
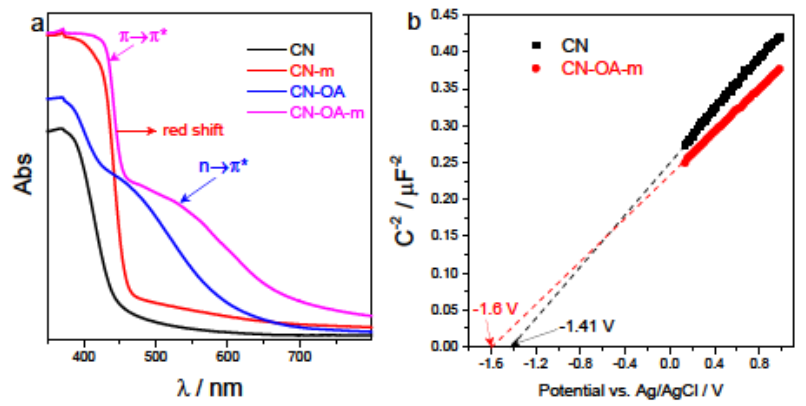

Figure 2. (a) UV-vis absorption spectra of $\mathrm{CN}, \mathrm{CN}-\mathrm{M}, \mathrm{CN}-\mathrm{OA}$ and $\mathrm{CN}-\mathrm{OA}-\mathrm{m}$ (b) Mott-Schottky plots of $\mathrm{CN}$ and $\mathrm{CN}-\mathrm{OA}-\mathrm{m}$ electrodes.

The second relevant change lies in the modification of the optical properties. As shown in Figure 2a, the salt treated samples, e.g. CN-OA-m, shows a notable enhanced optical absorption in both UV and visible light region. The intrinsic absorption band originates from the $\Pi \rightarrow \Pi^{\star}$ electron transition of the $\mathrm{sp}^{2}$ hybridization of $\mathrm{C}$ and $\mathrm{N}$ in the $\mathrm{CN}$ framework is clearly red-shifted to the visible light region by about $0.2 \mathrm{eV}$, and the band gap is decreased from 2.74 to $2.56 \mathrm{eV}$. We attribute the reinforced $\Pi \rightarrow \pi^{\star}$ electron transition in the conjugated aromatic ring system to the tighter and better packing of the joint heptazine system. ${ }^{[34]}$ Besides, an obvious new absorption band forms in the region from $462 \mathrm{~nm}$ to $700 \mathrm{~nm}$. This new band is usually ascribed to the $n \rightarrow \pi^{\star}$ electron transition involving the lone pairs of the edge nitrogen atoms in heptazine units. ${ }^{[31]}$ It is noteworthy that this electron transition is forbidden for perfectly symmetric and planar units, but the present structure is charged and polarized, and the shortened stacking distance between two layers is able to access this electron transition of $\mathrm{CN}-\mathrm{OA}-\mathrm{m}$ with an only slightly diminished resonator strength, when compared to the $\pi \rightarrow \pi^{*}$ transition. The creation of new absorption bands can potentially be utilized for photochemistry with visible light with wavelength longer than $500 \mathrm{~nm}$, however then leaving a differently localized electron hole in the chemical structure. MottSchottky curves (Figure $2 \mathrm{~b}$ and $\mathrm{S} 7$ ) revealed that the relative conduction band minimum (CBM) of $\mathrm{CN}-\mathrm{OA}-\mathrm{m}$ was $-1.6 \mathrm{~V}$, very similar to that of the pristine $\mathrm{CN}(-1.4 \mathrm{~V})$, consistent with the 
UPS results (Figure S8). These positions thermodynamically enable the rapid proton reduction for $\mathrm{H}_{2}$ evolution.
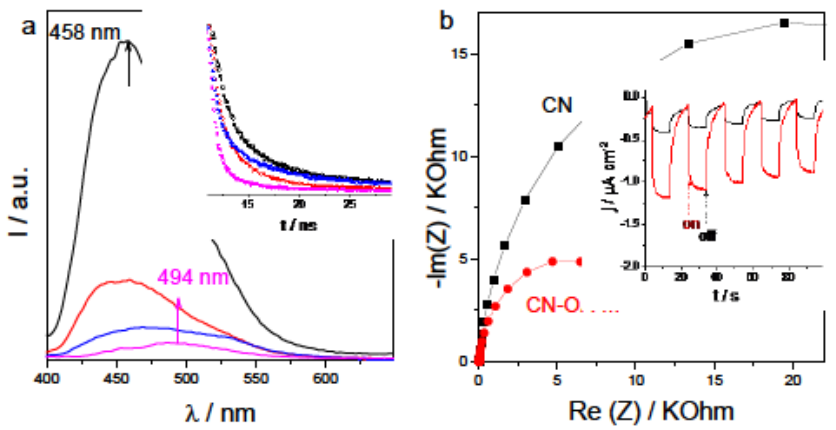

Figure 3. (a) Room temperature ( $298 \mathrm{~K})$ steady-state PL spectra, inset: timeresolved fluorescence kinetics monitored at the corresponding emission peaks of $\mathrm{CN}, \mathrm{CN}-\mathrm{OA}, \mathrm{CN}-\mathrm{m}$, and $\mathrm{CN}-\mathrm{OA}-\mathrm{m}$ and (b) electrochemical impedance spectroscopy (EIS) Nyquist Plots under visible light irradiation, inset: transient photocurrent conducted with a bias potential of $-0.2 \mathrm{~V}$ of $\mathrm{CN}$ and $\mathrm{CN}-\mathrm{OA}-\mathrm{m}$.

The excitonic processes of the samples were monitored by steady-state photoluminescence (PL) measurements. In Figure 3a, CN-OA-m exhibits obviously reduced emission intensity with respect to pristine $\mathrm{CN}$. Time-resolved fluorescence spectra monitored at the corresponding emission peaks gives the mean radiative lifetimes $\left(A_{\tau}\right)$ of the recombining charge carriers (Figure $3 a$ inset). The $A_{\tau}$ of $\mathrm{CN}, \mathrm{CN}-\mathrm{m}, \mathrm{CN}-\mathrm{OA}$ and $\mathrm{CN}-\mathrm{OA}-\mathrm{m}$ were $15.37,8.07,11.31$, and 5.65 ns, respectively (lifetime components see Table S2). As this decreased singlet exciton lifetime of the optimized samples obviously implies enhanced exciton dissociation, i.e. only the very fast charge pairs can recombine. It is most likely that shortened layer distance in the crystalline polymers accelerates the charge transfer over the layers, promoting the singlet excitons to dissociate (tunneling of electrons and holes is usually very different, due to the different orbital symmetries), then also promotes the fast charge carrier migration from bulk to interface without recombination. The improved charge transport can be very classically certified by the decreased hemicycle radius in electrochemical impedance spectroscopy (EIS) and increased photocurrent, reflecting lower electric resistance of the material as shown in Figure $3 \mathrm{~b}$.

To check the influence of this optimization on photocatalysis in general, photocatalytic $\mathrm{H}_{2}$ evolution was conducted for all asprepared samples. Optimizations of the polymerization temperature are concluded in Figure S9. In the first place, we examined the photocatalytic activities by using white LED as the light source. Figure 4a shows that both $\mathrm{CN}-\mathrm{m}$ and $\mathrm{CN}-\mathrm{OA}-\mathrm{m}$ possess dramatically enhanced $\mathrm{H}_{2}$ evolution activities in comparison with pristine $\mathrm{CN}$. In particular, $\mathrm{CN}$-m exhibits ultrahigh $\mathrm{H}_{2}$ evolution activity $\left(150 \mu \mathrm{mol} \mathrm{h}{ }^{-1}\right)$, which is $\sim 30$ times higher than that of $\mathrm{CN}\left(5 \mu \mathrm{mol} \mathrm{h} \mathrm{h}^{-1}\right)$. CN-OA-m shows slightly lower activity $\left(84 \mu \mathrm{mol} \mathrm{h}^{-1}\right)$ than $\mathrm{CN}-\mathrm{m}$ but still much higher $(\sim 17$ times) than that of $\mathrm{CN}$.

It is exciting to observe that $\mathrm{CN}-\mathrm{m}\left(509 \mu \mathrm{mol} \mathrm{h}^{-1}\right)$ and $\mathrm{CN}-\mathrm{OA}$ $\mathrm{m}\left(210 \mu \mathrm{mol} \mathrm{h}{ }^{-1}\right)$ show ultrahigh activity when we use colloid chemistry to improve local electric fields at the surface, here by ion adsorption in the Helmholtz layer and by performing the same reactions in modelled sea water ( 3 wt. \% $\mathrm{NaCl}$ ). Interestingly this improvement only works for the highly crystalline samples, while no obvious improvement was found for $\mathrm{CN}$ and $\mathrm{CN}-\mathrm{OA}$. When same amounts of $\mathrm{LiCl}$ or $\mathrm{KCl}$ were used instead of $\mathrm{NaCl}$, very similar $\mathrm{H}_{2}$ evolution rate (Figure S10) was obtained for $\mathrm{CN}-\mathrm{m}$ under same conditions. Other simple salts, such as $\mathrm{K}_{2} \mathrm{HPO}_{4}$ (described as electron mediator) ${ }^{[9]}, \mathrm{KBr}$ and $\mathrm{Na}_{2} \mathrm{SO}_{4}$, also promote the $\mathrm{H}_{2}$ evolution, however, the activities are lower than that when using chlorides. Regarding the standard redox potential of chlorine $(\sim 1.36 \mathrm{~V})$, oxidation of $\mathrm{Cl}^{-}$is clearly within the reactivity of the hole of the photocatalysts. However, no free chlorine could be detected, i.e. the buffering species (e.g., oxychloride, hypochloride) stays surface bound.
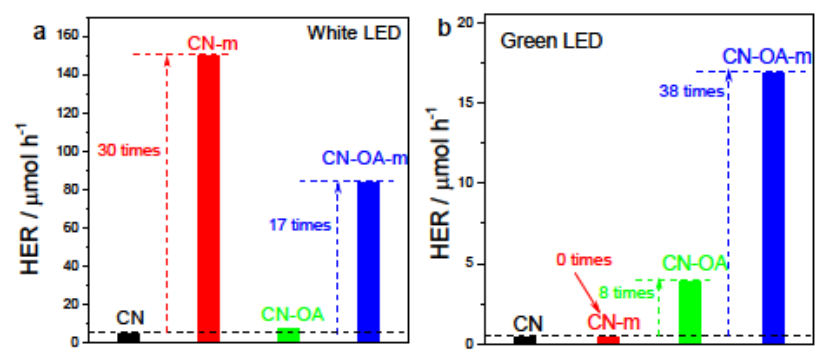

Figure 4. Photocatalytic $\mathrm{H}_{2}$ evolution activities of the as-prepared samples under (a) white and (b) green LED lights irradiation.

The designated advantage of the optimized $\mathrm{CN}-\mathrm{OA}-\mathrm{m}$ was the significantly enhanced light absorption above $500 \mathrm{~nm}$, and that is why we further examine the photocatalytic activities with longer wavelength (Figure S11). When performing photocatalytic $\mathrm{H}_{2}$ evolution with green LED ( $\lambda=525 \mathrm{~nm}$ ) (Figure 4b), CN and $\mathrm{CN}-\mathrm{m}$ are barely active in this wavelength region. On the contrary, $\mathrm{CN}-\mathrm{OA}$ and $\mathrm{CN}-\mathrm{OA}-\mathrm{m}$ express very unusual $\mathrm{H}_{2}$ evolution activities with green LED illumination. Having such an extra in-plane optical absorption does not necessarily translate in photochemical activity, as the generated hole has in our case a lower oxidation power (note that, as discussed above, that the reduction power of the electron is similar) and a different location onto the material to react from. However, CN-OA-m presents a comparably high activity $\left(17 \mu \mathrm{mol} \mathrm{h}^{-1}\right)$, nicely seen in comparison with other counterparts, certifying that this material is indeed active in the green region. In principle, only few of conjugated polymers have been reported to be active in this wavelength. ${ }^{[35]}$ The apparent quantum yield (AQY) of the optimized samples in the presence of $\mathrm{NaCl}$ is examined to reach $57 \%$ and $10 \%$ at 420 and $525 \mathrm{~nm}$, respectively, which is indeed much higher than most of the current polymeric photocatalysts. It is probably that chlorine is tightly bound in the Helmholtz layer around the particles act as electron donor, thereby accelerating the reaction to the rate of the reduction side, which is however very fast. TEOA under those conditions is still needed to close the catalytic cycle, but reaction takes place in an accelerated fashion and thus significantly promotes the photocatalytic activities. ${ }^{[36]}$

Besides, this optimized polymeric photocatalyst experiences robust recyclability and absence of light and solution corrosion. No evident decay in the activity and no structural difference 
could be detected (Figure S12 and 13) after four runs of persistent reaction, again illustrating the extraordinary stability for sustainable applications. The modification in the charge carrier transfer could also benefit the photocatalytic water oxidation process (Figure S14).

In summary, a facile strategy has been presented to tailor the texture and electronic band structure of polymeric carbon nitride. Owing to an obviously reduced interlayer stacking distance and extended spectral absorption, more photons can be turned into dissociated, reactive surface charges, as reflected by a dramatically improved visible light $\mathrm{H}_{2}$ evolution activity, especially in the light region above $500 \mathrm{~nm}$. This study highlights the synergistic optimization of crystal structure and D-Acopolymerization to significantly advance the exciton dissociation and hot charge carrier yield. It opens a new avenue to optimize the physicochemical properties of polymeric light collectors, which offers many opportunities for advanced photochemistry in general and their sustainable utilizations.

\section{Acknowledgements}

Dr. G. G. Zhang thanks the AvH (Alexander von Humboldt) Foundation for a postdoctoral fellowship. This work was financially supported by Max Planck Society and the National Basic Research Program of China (2013CB632405), the National Natural Science Foundation of China (21425309 and 21761132002) and the 111 Project.

Keywords: Water splitting $\bullet \mathrm{H}_{2}$ production $\cdot$ Carbon nitride $\cdot$ van der Waals Stacking $\bullet$ Exciton dissociation

[1] F. Kessier, Y. Zheng, D. Schwara, C. Merschjann, W. Schnick, X. Wang M. Bojdys, Nat. Rev. Mater. 2017, 2, 17030

[2] Y. Xu, S. Jin, H. Xu, A. Nagai, D. Jiang, Chem. Soc. Rev. 2013, 42, 8012-8031.

[3] J. Ran, T. Ma, G. Gao, X. Du, S. Qiao, Energy Environ. Sci. 2015, 8, 3708-3717.

[4] R. Sprick, B. Bonillo, R. Clowes, P. Guiglion, N. Brownbill, B. Slater, F Blanc, M. Zwijnenburg, D. Adams, A. Cooper, Angew. Chem. Int. Ed. 2016, 55, 1792-1796.

[5] X. Wang, K. Maeda, A. Thomas, K. Takanabe, G. Xin, J. M. Carlsson, K. Domen, M. Antonietti, Nat. Mater. 2009, 8, 76-80.

[6] M. Bhunia, K. Yamauchi, K. Takanabe, Angew. Chem. Int. Ed. 2014, 53, 11001-11005.

[7] L. Li, Z. Cai, Q. Wu, W. Lo, N. Zhang, L. Chen, L. Yu, J. Am. Chem. Soc. 2016, 138, 7681-7686.

[8] D. Martin, P. Reardon, S. Moniz, J. Tang, J. Am. Chem. Soc. 2014, 136, 12568-12571.

[9] G. Liu, T. Wang, H. Zhang, X. Meng, D. Hao, K. Chang, P. Li, T. Kako, J. Ye, Angew. Chem. Int. Ed. 2015, 54, 13561-13565.

[10] Y. Wang, X. Wang, M. Antonietti, Angew. Chem. Int. Ed. 2012, 51, 6889.

[11] Q. Han, B. Wang, Y. Zhao, C. Hu, L. Qu, Angew. Chem. Int. Ed. 2015 , 54, 11433-11437.

[12] K. Schwinghammer, B. Tuffy, M. B. Mesch, E. Wirnhier, C. Martineau, F. Taulelle, W. Schnick, J. Senker, B. Lotsch, Angew. Chem. Int. Ed. 2013 52, 2435-2439.

[13] C. Yang, B. Wang, L. Zhang, L. Yin, X. Wang, Angew. Chem. Int. Ed 2017, 56, 6627-6631.
[14] H. Wang, X. Sun, D. Li, X. Zhang, S. Chen, W. Shao, Y. Tian, Y. Xie, J. Am. Chem. Soc. 2017, 139, 2468-2473.

[15] G. Mane, S. Talapaneni, K. Lakhi, H. Ilbeygi, U. Ravon, K. Al-Bahily, T. Mori, D. Park, A. Vinu, Angew. Chem. Int. Ed. 2017, 56, 8481-8485.

[16] P. Yang, H. Ou, Y. Fang, X. Wang, Angew. Chem. Int. Ed. 2017, 56 3992-3996.

[17] P. Niu, L. Yin, Y. Yang, G. Liu, H. Cheng, Adv. Mater. 2014, 26, 8046 8052

[18] Z. Lin, X. Wang, Angew. Chem. Int. Ed. 2013, 52, 1735-1738.

[19] Y. Guo, J. Li, Y. Yuan, L. Li, M. Zhang, C. Zhou, Z. Lin, Angew. Chem Int. Ed. 2016, 55, 14693-14697.

[20] G. Algara-Siller, N. Severin, S. Y. Chong, T. Bjçrkman, R. Palgrave, A Laybourn, M. Antonietti, Y. Khimyak, A. Krasheninnikov, J. Rabe, U Kaiser, A. Cooper, A. Thomas, M. Bojdys, Angew. Chem. Int. Ed. 2014 53, 7450-7455.

[21] Y. Zheng, L. Lin, B. Wang, X. Wang, Angew. Chem. Int. Ed., 2015, 54, 12868-12884

[22] A. Thomas, A. Fischer, F. Goettmann, M. Antonietti, J. Müller, R. Schlöglb, J. Carlsson, J. Mater. Chem. 2008,18, 4893-4908.

[23] L. Lin, H. Ou, Y. Zhang, X. Wang, ACS Catal. 2016, 6, 3921-3931.

[24] S. Park, A. Roy, S. Beaupre, S. Cho, N. Coates, J. Moon, D. Moses, M. Leclerc, K. Lee, A. J. Heeger, Nat. Photon. 2009, 3, 207-303.

[25] a) G. Zhang, M. Zhang, X. Ye, X. Qiu, S. Lin, X. Wang, Adv. Mater 2014, 26, 805-809; b) X. Fan, L. Zhang, R. Cheng, M. Wang, M. Li, Y. Zhou, J. Shi, ACS Catal. 2015, 5, 5008-5015

[26] S. Guo, Z. Deng, M. Li, B. Jiang, C. Tian, Q. Pan, H. Fu, Angew. Chem Int. Ed. 2016, 55, 1830-1834.

[27] G. Liu, P. Niu, L. Yin, H. Cheng, J. Am. Chem. Soc. 2012, 134, 9070 9073

[28] a) J. Zhang, X. Chen, K. Takanabe, K. Maeda, K. Domen, J. Epping, X Fu, M. Antoniet i, X. Wang, Angew. Chem. Int. Ed. 2010, 49, 441-444; b) Y. Jun, J. Park, S. Lee, A. Thomas, W. Hong, G. D. Stucky, Angew. Chem. Int. Ed. 2013, 52, 11083-11087

[29] J. Zhang, G. Zhang, X. Chen, S. Lin, L. Möhlmann, G. Dołęga, G. Lipner, M. Antonietti, S. Blechert, X. Wang, Angew. Chem. Int. Ed. 2012, 51, 3183-3187.

[30] M. Zhang, X. Wang, Energy \& Environ. Sci. 2014, 7,1902-1906.

[31] G. Zhang, A. Savateev, Y. Zhao, L. Li, M. Antonietti, J. Mater. Chem. A 2017, 5, 12723-12728.

[32] M. Bojdys, J. Muller, M. Antoniet i, A. Thomas, Chem. Eur. J. 2008, 14, 8177-8182.

[33] A. Savateev, S. Pronkin, J. Epping, M. Willinger, C. Wolff, D. Neher, M. Antonietti, D. Dontsova, ChemCatChem 2017, 9, 167-174.

[34] a) T. Ma, S. Dai, M. Jaroniec, S. Qiao, Angew. Chem. Int. Ed. 2015, 54 4646-4650; b) X. Li, W. Bi, L. Zhang, S. Tao, W. Chu, Q. Zhang, Y. Luo C. Wu, Y. Xie, Adv. Mater. 2016, 28, 2427-2431; c) G. Zhang, Z. Lan, L. Lin, S. Lin, X. Wang, Chem. Sci. 2016, 7, 3062-3066.

[35] G. Zhang, Z. Lan, X. Wang, Angew. Chem. Int. Ed. 2016, 55, 1571215727.

[36] J. Li, C. Ye, X. Li, Z. Li, X. Gao, B. Chen, C. Tung, L. Wu, Adv. Mater. 2017, 29, 1606009 